\title{
Lecturas críticas y oposicionales de películas de Hollywood por jóvenes mexicanos: el caso de Ángeles y Demonios*
}

\author{
(2) \\ José Carlos Lozano Rendón ** \\ Lorena Frankenberg \\ Recibido: 17 de enero de 2011 Aprobado: 7 de marzo de 2011
}

\section{Resumen}

Al igual que en muchos otros países del mundo, las superproducciones de Hollywood son sumamente exitosas en el mercado mexicano. Cada año, millones de personas van a las salas de cine y ven numerosas películas procedentes del poderoso vecino del Norte. A pesar de la fuerte popularidad de los estudios culturales en México y la histórica preocupación en el país por el impacto ideológico de las importaciones audiovisuales estadounidenses en la identidad cultural de las audiencias, los estudios empíricos sobre lecturas específicas de películas extranjeras han sido muy escasos. Este trabajo discute los hallazgos de 10 entrevistas focalizadas y 5 grupos de enfoque con jóvenes de Monterrey, México sobre sus lecturas de la película de Hollywood Ángeles y Demonios, basada en la exitosa novela de Dan Brown. Los informantes fueron estudiantes de licenciatura de una universidad privada. Para evitar que estuvieran demasiado familiarizados con las teorías de la comunicación o con la metodología empleada, los participantes fueron seleccionados de programas académicos que no se relacionaran con las humanidades ni las ciencias sociales. Este trabajo explora el grado en que los jóvenes fueron capaces de establecer una distancia crítica ante el filme, clasificando sus comentarios sobre éste en una categoría denominada "no oposicional" y cuatro categorías de comentarios oposicionales: crítica, resistencia, desafío y deconstrucción. Los hallazgos muestran que la mayoría de los comentarios de los entrevistados no eran críticos hacia el contenido del filme y que las pocas aseveraciones oposicionales externadas eran superficiales y poco elaboradas. Por otro lado, el bagaje religioso católico de muchos de los jóvenes parecía constituir una mediación clara y fuerte en sus lecturas. El artículo concluye con una discusión sobre las implicaciones de los hallazgos en el contexto de las aportaciones de estudios culturales al análisis de las lecturas negociadas, las mediaciones sociales y los procesos de apropiación.

Palabras clave: Descodificación de filmes, estudios de audiencias, estudios culturales, lecturas negociadas de contenidos mediáticos, recepción.

\footnotetext{
Este reporte se basa en un estudio realizado con el apoyo de alumnos de la materia de Métodos Cuantitativos de Investigación impartida en el verano de 2009 en el Tecnológico de Monterrey, Campus Monterrey, México. Los autores agradecen la participación de los alumnos Héctor Alejandro Castillo, Saúl Alejandro Martínez, Elda Grecia Zapata, Ana Cristina Ochoa, Myriam Alexandra Tamez, Ana Cynthia Martínez, Marcela Chapa, Trinidad del Buen Suceso Barrera, Kristian Andrés Macías, Scarlett Ávila, Andrea Noroña, Alejandra Chaveznava, Alberto Pechard y Ana Venegas.

2 Licenciado en Ciencias de la Comunicación Social por la Universidad Regiomontana, maestría en Comunicación de Masas por la Universidad de Leicester, Inglaterra, doctorado en Comunicación Internacional por la Universidad de Texas en Austin. Es miembro del Sistema Nacional de Investigadores en el nivel 3 del Consejo Nacional de Ciencia y Tecnología (Conacyt) de México y Miembro Regular de la Academia Mexicana de Ciencias. Es director del Centro de Investigación en Comunicación e Información (CINCO) y titular de la Cátedra de Investigación en Medios de Comunicación en el Tecnológico de Monterrey.

3 Licenciada en Ciencias de la Información y Comunicación, y maestra en Humanidades por la Universidad de Monterrey, obtuvo el doctorado en Estudios Humanísticos con especialidad en Estudios Culturales y Comunicación en el Tecnológico de Monterrey. Actualmente realiza una investigación Posdoctoral con el grupo de investigación "Mediatized Worlds" de la Universidad de Bremen, Alemania. Es Directora del Instituto de Comunicación Digital y del Centro Interdisciplinario de Investigación Social Aplicada de la Universidad Metropolitana de Monterrey. Miembro del Sistema Nacional de Investigadores en el nivel Candidato del Consejo Nacional de Ciencia y Tecnología (Conacyt) de México.
} 


\title{
Critical and oppositional readings of Hollywood films made by Mexican youngsters: the "Angeles y demonios" (Angels and devils) case
}

\begin{abstract}
As well as in many other countries worldwide, Hollywood super-productions are extremely successful in the Mexican market. Each year, million people go to movie theaters to watch several movies coming from the United States of America. Despite the strong popularity of cultural studios in Mexico and the historical concern in this country for the ideological impact of American audiovisual imports on the cultural identity of audiences, very few empirical studies about specific readings of foreign films have been conducted. This article tackles findings from 10 focused interviews and 5 focus groups with youngsters from Monterrey, Mexico about readings of the Hollywood film "Angeles and Demonios," (Angles and Devils) based on the successful novel written by Dan Brown. Informants were students from a private university. In order to avoid their strong familiarization with theories of communication or the methodology used, participants were selected from academic programs not related to humanities or social sciences. This article explores the level to which these youngsters were able to establish a critical distance before the film, classifying their comments on the film in a category called "not oppositional" and four categories for oppositional comments: critical, resistance, challenge, and deconstruction. Findings show that most comments from the interviewees were not critical toward the film content and the few oppositional comments expressed were superficial and poorly elaborated. On the other hand, the catholic religious background of most youngsters seemed to construct a clear and strong mediation in their readings. The article concludes with a discussion on the implications of the findings in relation to contributions of cultural studies to the analysis of negotiated readings, social mediations, and appropriation processes.
\end{abstract}

Key words: film decoding, audience studies, cultural studies, negotiated readings of media contents, reception. 
Como en muchos otros países del mundo, las superproducciones de Hollywood son sumamente exitosas en el mercado mexicano. Cada año, millones de personas asisten a las salas de cine y ven películas procedentes del poderoso vecino del Norte.

De acuerdo con algunos estudios, entre el 80 y el $90 \%$ de todas las funciones en el país las ocupan cintas estadounidenses. Las grandes distribuidoras norteamericanas controlan la distribución de películas en México y la cuota del 10\% de tiempo de pantalla para producciones nacionales, a pesar de su reducción del 50\% que experimentó al entrar el Tratado de Libre Comercio, con frecuencia no se alcanza por la falta de filmes realizados en el país.

De acuerdo con el director de la Motion Picture Association (MPA) en México Federico de la Garza, los ingresos totales por la exhibición de películas en las salas nacionales durante 2009 fue de $\$ 7,854,000$ pesos mexicanos (alrededor de $\$ 654,500$ USD), lo que representaba un incremento del 10\% en comparación con el 2008. De la Garza agregó que esa cantidad se había logrado gracias principalmente a la exhibición de grandes producciones de Hollywood como Avatar y la Era de Hielo 3 (Meré, 26 de febrero, p. 4). Alejandro Ramírez, presidente de la Cámara Nacional de la Industria Cinematográfica, calculó con base en los 182 millones de entradas vendidas en 2008 que en ese año cada mexicano había asistido a salas de cine 1.7 veces (Meré, 2009, 2 de noviembre, p. 5).

El predominio del enfoque del imperialismo cultural en los setenta y principios de los ochenta en México y América Latina generó frecuentes acusaciones sobre la erosión de la identidad cultural y sobre el impacto ideológico de los contenidos mediáticos en los miembros de las audiencias de la región (Beltrán y Fox de Cardona, 1980; Dorfman y Mattelart 1975; Esteinou, 1983, 1994; Mattelart, 1979). En los noventa y en la década de los dos mil, sin embargo, la popularidad de diferentes escuelas vinculadas a los estudios culturales en la región ha propiciado la adopción de visiones más optimistas sobre la actividad y la capacidad de las audiencias para negociar los sig- nificados ideológicos incorporados en los mensajes comunicacionales (González, 1996; Jacks, 1993; La Pastina, 2007; Lozano, 2003; Martín Barbero, 1987; Saintout, 1998) y sobre la presencia de mediaciones sociales y culturales que actúan como filtros entre los contenidos ideológicos de los medios y los individuos (Martín Barbero, 2006; Orozco, 1991). La investigación empírica sobre la recepción de cine y las lecturas específicas de filmes que puedan documentar la asumida actividad de las audiencias, sin embargo, es casi inexistente. Los pocos estudios empíricos que se enfocan en la descodificación y apropiación de contenidos mediáticos por diferentes tipos de públicos se han enfocado en los programas televisivos, centrados no en las lecturas ideológicas de dichos programas (para una revisión integral de la investigación latinoamericana de audiencias televisivas véase Lozano y Frankenberg, 2009) sino en otros aspectos, como la integración de la televisión en la vida cotidiana de las audiencias (González, 1998; González, 2007; Guadarrama, 1999; Huerta, 2004, La Pastina, 2007; Yarto y Lozano, 2004; Tufte, 2000; Uribe, 1994; Vega, 2005) o, por ejemplo, en las mediaciones ejercidas por las madres en la recepción televisiva de sus hijos (Orozco, 1992).

De acuerdo con investigadores culturalistas que se han enfocado en la descodificación de contenidos mediáticos por las audiencias ya sea de manera teórica

(Hall, 1980/2001; Morley, 2006) o empírica (Ang, 1985; Hacker, Coste y Kamm, 1991; Morley, 1980) los miembros de las audiencias son activos y capaces de realizar lecturas preferentes, negociadas u oposicionales de los mensajes, dependiendo de su clase social (Hall, 1980/2001), sus identidades étnicas o de género (Hobson, 1989; Nigthingale, 1996) o sus mediaciones sociales y culturales (Martín Barbero, 1987; Orozco, 1991). Las lecturas preferentes son aquellas que interpretan el texto tal como lo sugerían sus creadores en consonancia con los valores sociales hegemónicos. Las lecturas oposicionales descodifican los contenidos dominantes desde un marco de referencia alternativo. En palabras de Hall (1980/2001): "El receptor detotaliza el 
mensaje en el código preferente para retotalizarlo dentro de un marco de referencia alternativo" (p. 175). La mayoría de los miembros del público, sin embargo, tienden a realizar lecturas negociadas, una mezcla de elementos adaptativos y oposicionales: "se acepta la legitimación de las definiciones hegemónicas al hacer las significaciones generales (abstractas), mientras que en un nivel más restringido, situacional, se establecen sus propias reglas del juego -operando con excepciones a las reglas" (p. 175).

Algunos teóricos como Schroder (2000) han cuestionado este modelo argumentando que no permite incluir la descodificación de contenidos alternativos, no hegemónicos. Para él, lo que se requiere es un modelo multidimensional capaz de "distinguir entre los acuerdos o desacuerdos subjetivos experimentados por el receptor con el texto mediático (la posición del lector) y la evaluación del investigador sobre el papel jugado por las posiciones de los lectores en las contiendas contra la hegemonía". El académico afirma que el modelo de Hall se centra exclusivamente en mensajes que representan los intereses hegemónicos de las clases dominantes, dejando a un lado otro tipo de lecturas ideológicas:

Esto descalifica la parte sobre la descodificación en el modelo en cuanto a modelo general de recepción, pues simplemente no está equipada para enfrentar otros escenarios ideológicos como por ejemplo "una lectura conservadora de un programa televisivo encodificado con un significado preferente socialista". (p. 240)

En la misma línea, Cohen (2002) afirma que frecuentemente la posición ideológica de un texto es disputable y ambigua, haciendo difícil determinar cuál debería ser considerado una posición hegemónica y cuál una posición de resistencia (p. 258). Agrega que mientras que en los estudios culturalistas sobre noticias es más fácil coincidir con la interpretación de cuál es el contenido ideológico dominante del mensaje, en los programas narrativos de televisión (o en las películas, en este caso) la identificación con los personajes principales puede ser una manera más fructífera de establecer la lectura hegemónica, mientras que una lectura oposicional "requiere que el televidente o cinéfilo se distancie psicológicamente de los héroes del programa para poder cuestionar ideológicamente el realismo del programa y resistir la suspensión de incredulidad"

(p. 258). Aunque este es un punto importante y necesita ser tomado en cuenta en cualquier evaluación del tipo de lecturas realizadas por los miembros de las audiencias en la ficción, consideramos que eso no debería dejar a un lado el análisis de los múltiples significados hegemónicos y alternativos que se pueden encontrar en el contenido, las tramas y aún en la representación de lugares y cosas en los programas televisivos de ficción o en las películas comerciales.

Hacker, Coste y Kamm (1991) proponen una forma muy útil para identificar de manera más precisa y detallada el grado de resistencia y distanciamiento crítico de las audiencias en relación con los contenidos mediáticos. Ellos desarrollaron cuatro categorías que representan niveles cada vez más intensos de oposición ante los significados incluidos en los textos mediáticos: crítica, resistencia, desafío y deconstrucción (p. 187). Consecuentemente, no sólo intentaron identificar la presencia o ausencia de descodificaciones oposicionales, sino explorar y describir diferentes tipos de lecturas oposicionales. De acuerdo con su modelo, el término "crítica" es usado para clasificar comentarios críticos sin fundamentos o respaldo ("No me gusta tal noticiero de televisión"), "resistencia" se refiere a críticas acompañadas de falta de credibilidad o confianza, y "desafío" se reserva para críticas de hecho con explicaciones alternativas (basadas en fuentes externas al texto mediático o al propio conocimiento del receptor, como, en una noticia, señalar: "No creo que hayan muerto solamente 100,000 personas. Yo escuché que fueron 500,000"). El cuarto término, "deconstrucción", se utiliza para el más alto nivel de apreciación crítica de un mensaje mediático: la identificación y cuestionamiento por parte del receptor de los procesos o intereses ideológicos en los contenidos de los medios, como el comentario: "No me gusta el noticiero de la CBS porque las noticias de las cadenas son puro negocio y por lo tan- 
to sesgadas a favor de intereses económicos". Inspirados en este trabajo de Hacker, Coste y Kamm, pero interesados en aplicarlo a la ficción televisiva-la recepción de series norteamericanas por adolescentes alemanes_-Palmer y Hafen (1999) adaptaron el modelo reduciéndolo a sólo dos categorías oposicionales: "rechazo sofisticado" y "deconstrucción" pero añadiendo dos nuevas categorías para las lecturas dominantes: "aceptación ingenua" y "aceptación sofisticada", lo que les permitió tomar en cuenta no sólo las lecturas críticas sino también las interpretaciones favorables a los significados dominantes en los textos (p. 136).

El concepto de mediaciones sociales y culturales elaborado por teóricos latinoamericanos también resulta relevante cuando se busca entender los factores que influyen en la descodificación de cualquier texto mediático. De acuerdo con Martín Barbero, uno de los espacios de interpretación y descodificación, claves para el individuo, es "la cotidianidad familiar", la cual filtra la experiencia de sus miembros en sus rutinas diarias de exposición a los medios (p. 233). De igual forma, en su estudio sobre la influencia de la familia en la recepción de telenovelas en televidentes mexicanos, Uribe (1994) vio a la familia como un sistema abierto en el que la relación e interacción entre sus miembros interviene en el tipo de lecturas que cada individuo particular hace de dicho género televisivo. Esta apropiación se da, por ejemplo, mediante comentarios que el grupo hace al reaccionar frente a la lógica del texto, ya sea en el momento en que se está viendo el programa o a lo largo del día (p. 203). Orozco (1991), al proponer una tipología de mediaciones en la recepción y apropiación de los mensajes televisivos, menciona la religión como otra de las mediaciones "institucionales" que actúan como filtros entre el individuo y el contenido de los medios. Por lo general, explica Orozco, los televidentes son miembros de una familia, miembros de un barrio y miembros de diferentes grupos. Además, van o han ido a la escuela y profesan una religión. En todas estas instituciones sociales el individuo interactúa, intercambia y produce significados. Estos sentidos y significa- dos proporcionados por cada institución social se fusionan en el individuo debido a su pertenencia simultánea a todas ellas. El resultado es que el receptor, al ver televisión o ir al cine, no se enfrenta a la pantalla con la mente en blanco, sino con actitudes, ideas y valores originados de múltiples fuentes, un repertorio cultural que usa para darle sentido y procesar los significados de los contenidos mediáticos.

Debido a nuestro interés en explorar a fondo el grado de distanciamiento crítico y la habilidad de los cinéfilos mexicanos para cuestionar y deconstruir las películas de Hollywood, decidimos usar las cuatro categorías de comentarios oposicionales de Hacker, Coste y Kamm tal como las desarrollaron, pero aplicándolas no a la descodificación de noticias sino a la de una superproducción de Hollywood que se exhibía en el verano de 2009 en las salas de Monterrey: Ángeles y Demonios. Además, en la misma línea que Palmer y Hafen (1999) agregamos una categoría para "comentarios no oposicionales", para poner en perspectiva los oposicionales y evaluar qué tan frecuentes y relevantes eran estos últimos. Finalmente, buscamos identificar explícitamente la relevancia de mediaciones sociales y culturales como la religión y la familia en las descodificaciones de los jóvenes, siguiendo la rica tradición teórica en América Latina sobre la influencia de mediaciones como esas en la socialización de los individuos y su papel como filtros en la interpretación de los mensajes mediáticos. Al hacer lo anterior, buscamos contribuir al creciente número de estudios empíricos sobre lecturas de filmes estadounidenses en países distintos a Estados Unidos, para poner a prueba las afirmaciones de los estudios culturales sobre la actividad de la audiencia y los efectos de mediaciones sociales como cultura, edad, género y religión en la descodificación de los contenidos ideológicos de cintas extranjeras.

\section{Ángeles y demonios}

Basado en el best seller de Dan Brown, Ángeles y Demonios fue una superproducción de Hollywood que se estrenó en mayo de 2009 a escala mundial. 
Dirigido por Ron Howard, el film fue estelarizado por Tom Hanks (como Robert Langdong), Ewan McGregor (como el camarlengo Patrick McKenna) y Ayelet Zurer (como Vittoria Vetra). En octubre de 2010 la película fue listada en el lugar 82 de las 100 películas más taquilleras de todos los tiempos de acuerdo con sus ingresos mundiales (Dirks, 2010). El ingreso total durante el verano de 2009 en las salas de cine mexicanas fue de $\$ 13,379,208$ USD, convirtiendo a Ángeles y Demonios en el octavo filme más taquillero en el país durante 2009 ("Box office mojo," 2010). Aunque por un lado esta película llegó a México dentro del flujo permanente de cintas estadounidenses y se mercadeó utilizando la misma base de distribución a través de las majors norteamericanas, sin duda alguna tuvo una atracción especial en las audiencias mexicanas debido a la intensa controversia generada por su antecesora, El Código da Vinci, por las críticas abiertas realizadas por la Iglesia Católica a su contenido.

La Internet Movie Data Base ofrece el siguiente sumario de la trama de la película:

Bajo los vigilantes ojos del Padre Silvano Bentivoglio y la Dra. Vittoria Vetra, la Organización Europea para la Investigación Nuclear (CERN) hace funcionar el Gran Colisionador de Hadrones (Large Hadron Collider) y captura tres recipientes de antimateria. Inmediatamente después, alguien asesina al Padre Silvano, usando su retina para infiltrar la cámara de contención y robar uno de los recipientes.

La Iglesia Católica Romana llora la muerte del Papa Pío XVI en Roma, donde el Vaticano prepara el Cónclave del Colegio de Cardenales para seleccionar al nuevo Papa. Hasta ese momento, el camarlengo Patrick McKenna, oficial de la corte del Vaticano y antiguo piloto de helicóptero, asume el control temporal del Vaticano. Reporteros, monjas, sacerdotes y otros miembros fieles de la Iglesia se amontonan en la Plaza de San Pedro a esperar el humo blanco que emitirá el cónclave al llegar a un voto exitoso. Pero los Iluminati, una sociedad secreta de 400 años de antigüedad, rapta a cuatro de los candidatos más viables antes de que el cónclave entre en reclusión. Los Iluminati amenazan con matar uno cada hora, empe- zando a las 8:00 p.m., y destruir el Vaticano en una explosión de luz a la medianoche. Una cámara de seguridad robada muestra el frasco de antimateria, el cual explotará catastróficamente cuando al recipiente se le acabe la batería haciendo desaparecer el campo magnético que mantiene estable la antimateria.

El Vaticano manda llamar al simbologista Robert Langdon de la Universidad de Harvard y a Vittoria Vetra del CERN para que ayuden a resolver la amenaza de los Iluminati, salven a los cuatro prefereti y reemplacen las baterías del recipiente. Langdon escucha el mensaje de los Iluminati y deduce que los cuatro cardenales morirán en los cuatro altares de la "Senda de la Iluminación" [...]

IA pesar de los esfuerzos y la habilidad de Langdon para encontrar los sitios de cada asesinato mediante distintas pistas, el asesino logra matar a tres de ellos y sólo se salva uno]... El asesino escapa y encuentra un vehículo que le han dejado para su huida, pero que explota al encender el motor con la llave. Langdon y Vetra descubren que la victima final del complot sería el camarlengo McKenna... El camarlengo, Langdon, Vetra, y los Guardias Suizos descubren la ubicación del frasco robado de antimateria. Para cuando lo encuentran, la batería está a punto de expirar y la explosión mortal a unos cuantos minutos. El camarlengo toma el recipiente y usa un helicóptero que se encontraba disponible para evacuarlos del Vaticano, para alejar el recipiente del lugar, ascendiendo verticalmente lo más que puede. Ya arriba, pone en autopiloto el helicóptero y se lanza en paracaídas. Después de algunos segundos la bomba explota y el camarlengo aterriza, ya considerado como héroe por la multitud y considerado por el Colegio de Cardenales como el mejor candidato para convertirse en el nuevo Papa. Mientras tanto, Langdon y Vetra usan la llave de Richter para ver un video de seguridad que muestra que el cerebro detrás de los asesinatos del Papa original y de los preferetis así como del recipiente de antimateria era el camarlengo y no los Iluminati. Mientras el comandante de la Guardia Suiza Richter intenta arrestar a McKenna, el Padre se mar- 
ca a sí mismo con el hierro que contenía el símbolo de la crucifixión de San Pedro al revés y acusa al comandante de ser miembro de los Iluminati. Langdon muestra el video al Colegio y cuando el camarlengo se percata que su confabulación ha sido descubierta, se inmola cubriéndose de aceite de una de las 99 lámparas que se encuentran dentro de la Basílica de San Pedro.

El Vaticano anuncia que el camarlengo murió debido a las heridas internas producidas durante su aterrizaje mientras que el público exige que sea canonizado. El Colegio designa al Cardenal Baggia (el único sobreviviente de los cuatro cardenales raptados) como nuevo Papa, quien decide adoptar el nombre de Lucas, y al Cardenal Strauss como el nuevo camarlengo. Strauss agradece a Robert Langdon por salvar al Vaticano y al nuevo Papa, y como emblema de su gratitud le presta el libro de Galileo "Diagramma Veritas" a Langdon para que lo estudie. La película concluye con el nuevo Papa caminando hacia el balcón para saludar a la multitud que se encuentra en la Plaza de San Pedro. ("Synopsis for Angels \& Demons," 2010)

La película fue seleccionada debido a su representación controversial del Vaticano y de la Iglesia Católica. Por un lado, el filme muestra al Vaticano como un lugar de intrigas, corrupción y ambición política terrenal. El culpable final del asesinato de los tres cardenales raptados, del Papa y del sacerdote-científico que experimentaba con la antimateria es el camarlengo del Papa, quien deseaba aparecer como el héroe y salvador de la cristiandad de supuestos enemigos de la Iglesia. Por otro lado, la cinta describe a la Iglesia Católica como poderosa y central en la geopolítica de nuestra era, y presenta al Papa asesinado y al sacerdote-científico que trabajaba en el acelerador de partículas del CERN como creyentes progresistas en el poder y legitimidad de la ciencia para encontrar vínculos entre el Hombre y Dios. Esta ambivalencia, además de las referencias explícitas, múltiples y contradictorias a la política, la ciencia y la religión en el filme, lo convierte en un caso útil para la exploración de descodificaciones diferenciadas entre los ciné- filos de acuerdo con su cultura, su edad y sus creencias religiosas.

Las preguntas de investigación que guiaron este análisis fueron:

1. ¿Qué tipo de lecturas de Ángeles y Demonios fueron más frecuentes entre los jóvenes? ¿Fueron éstos capaces de establecer una distancia crítica frente al filme, cuestionando o evaluando sus posiciones ideológicas o políticas o identificando sus valores hegemónicos en su trama, personajes o aspectos formales?

2. ¿Marcaron diferencias en las lecturas oposicionales de los informantes mediaciones como la familia y la religión? ¿De qué forma?

\section{Método}

El trabajo de campo consistió en una investigación cualitativa de audiencias entre jóvenes universitarios del Tecnológico de Monterrey, México. Un total de 40 estudiantes entre 19 y 24 años de edad, cursando carreras no relacionadas con la comunicación ni las ciencias sociales y de nivel socioeconómico alto y medio alto, participaron en el estudio sobre la película Ángeles y Demonios.

El diseño metodológico incluyó dos técnicas cualitativas. Por un lado, se realizaron 10 entrevistas a profundidad y por otro 5 grupos de discusión con 6 informantes cada uno. En ambos casos, el requisito preliminar para participar como informante en el trabajo era haber visto la película en un lapso no mayor a dos semanas. En ambas modalidades, los estudiantes fueron cuestionados sobre su percepción, actitudes y opiniones acerca del contenido de la película. Las sesiones fueron grabadas, transcritas y codificadas utilizando el software HyperResearch.

Los cuestionarios de las entrevistas y los grupos focalizados fueron diseñados con el propósito de analizar las habilidades cognitivas de los jóvenes para descodificar y deconstruir el texto fílmico. Este diseño se basó principalmente en el trabajo de Hacker, Coste y Kamm (1991) en su investigación empírica de audiencias sobre la deconstrucción de contenidos noticiosos entre jóvenes. El instrumento de investigación incluyó 
preguntas generales sobre sus preferencias fílmicas, la frecuencia de visitas al cine y su experiencia social cinematográfica. Específicamente sobre Ángeles y Demonios, los jóvenes eran cuestionados sobre sus comentarios ideológicos, sobre las escenas de credibilidad o desconfianza hacia el texto y su percepción sobre la representación de la Iglesia Católica en el largometraje.

Para la codificación, se dividieron los comentarios en dos categorías principales: oposicionales y no oposicionales. Dentro de los comentarios oposicionales, se utilizaron los cuatro tipos de comentarios construidos por estos mismos autores (ver Tabla 1). Adicional a esta tipología, se codificaron los comentarios que revelaran mediaciones que influyeran directamente en los tipos de lecturas entre los jóvenes.

Para asegurar la validez del trabajo, se codificaron sólo los comentarios que pudieran ser categorizados con seguridad dentro de alguno de los cinco tipos.

\section{Resultados}

La tabla 2 muestra el número de frecuencias de los cinco principales tipos de comentarios codificados en este estudio. El principal hallazgo de este estudio reside en que la mayoría de los jóvenes hicieron comentarios no oposicionales a la película. Los apuntes de los informantes fueron principalmente superfluos y en favor de aspectos generales de la historia. El siguiente es un ejemplo de un comentario no oposicional:

Muy bien, actúan muy bien. Es un poco seria la película, en el libro no es tan seria, pero es buena, me gusto la actuación, me gustó la muchacha esta... la científica, muy buena actuación de su parte, está muy ad hoc. El Camarlengo también estuvo perfecto. Y también los personajes del cónclave, aunque no hayan salido mucho yo digo que representan una muy buena parte de lo que es la Iglesia y... estuvo muy bien representada en todos los aspectos. (Alejandro-19)

Más allá de intentar determinar si los jóvenes hicieron lecturas preferentes, negociadas u oposicionales de un significado hegemónico-dominante del filme, decidimos codificar sus reacciones como oposicionales en el caso de que fueran capaces de distanciarse y ser críticos en la posición adoptada por el texto, y no oposicionales en el caso que estuvieran de acuerdo con las premisas y posturas del mismo. En el caso de Ángeles y Demonios, el texto podría ser interpretado como alternativo o hegemónico: la representación de la Iglesia Católica en la película podría ser alter-

Tabla 1.

Tipos de comentarios oposicionales

Crítica. Crítica del contenido sin sustento

Resistencia. Crítica que incluye falta de credibilidad o confianza en el contenido

Desafío. Crítica de hechos con una explicación en respuesta (ya sea de una fuente externa o del propio espectador)

Deconstrucción. identificación y crítica de procesos ideológicos dentro del texto fílmico
Ejemplo. No me gustó la película. No la volvería a ver.

Ejemplo. Otra película Hollywoodense con final fantasioso.

Ejemplo. Debemos analizar tanto la postura religiosa como la científica para evaluar la veracidad del filme.

Ejemplo. Es una película con intenciones políticas, como casi todas las de la industria norteamericana.

O: Es una película contra las creencias religiosas en línea con la ideología de Hollywood.

Tipo de Comentario No Oposicional

Ejemplo. Me gustó mucho la película. Así es justamente como funciona la Iglesia Católica

Fuente: elaboración propia 
nativa por criticar a una institución poderosa que ejerce gran influencia en las personas, o hegemónica por ser originada en la popular industria cinematográfica de un país poderoso donde el catolicismo no es la religión dominante y en la que se privilegian narrativas sesgadas o simplistas. Como ejemplo e ilustración, codificamos el comentario de Alejandro como no oposicional por no mostrar un distanciamiento crítico del texto al margen de si este último era hegemónico o alternativo.

De los 256 comentarios codificados, 163 correspondieron al tipo no oposicional mientras que sólo 93 fueron de carácter oposicional. La mayoría de los comentarios en oposición al contenido de la película estuvieron dentro de los primeros niveles de crítica o resistencia. Un total de 78 declaraciones se referían solamente a falta de credibilidad o confianza en el texto sin ninguna confrontación o información alternativa y con un mínimo de argumentos para sustentar los comentarios.

Tabla 2.

\section{Frecuencias por Tipo de Comentario}

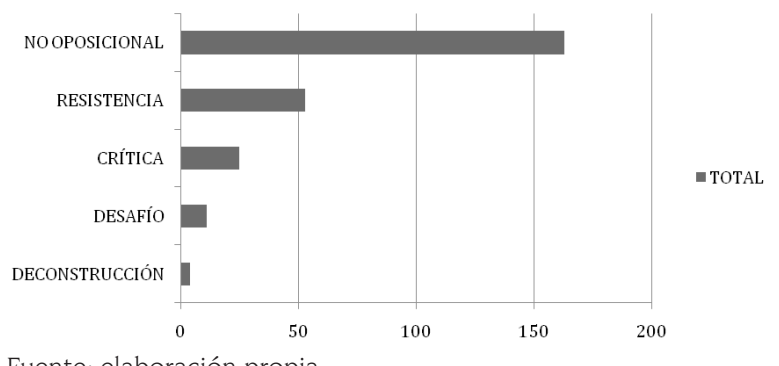

Fuente: elaboración propia

Estos comentarios oposicionales se referían básicamente a aspectos generales del guión, las actuaciones de los actores o las cuestiones artísticas de la producción. Uno de los jóvenes hizo el siguiente comentario (codificado como "crítica"):

No me gustó... Bueno pues obviamente varios cambios que se hicieron en la película que en el libro no son. De la mitad en adelante, cosas que pasan en la película, no pasan en el libro. Hay personajes que a mi punto de vista como lectora eran muy importantes, y hay personajes que se agrega que se me hacía estaban de más en la película, que en el libro no vienen (Daniela-20).

De los comentarios oposicionales, los de resistencia tuvieron un mayor número de menciones. El número más alto de este tipo hecho por un sólo informante fue de 12. Dos ejemplos de este tipo:

Bueno, a mí sí se me hace muy ofensivo porque nada más te dan la cara de la moneda donde la Iglesia es mala, te ponen a sacerdotes hablando por celular, con lentes... como que despilfarrando el dinero cuando en realidad la Iglesia también hace cosas muy buenas como esta... las misiones en África que yo creo que la verdad sí es una friega y no todos podríamos hacer eso, entonces, está un poco ofensiva en cuanto que nada mas enseña un lado de la Iglesia... el lado malo, pues, de lo que es y no te enseña las dos partes, lo malo y lo bueno que yo digo que si los contrastas, lo bueno termina siendo algo mayor a lo malo o a lo que... (Pedro-19)

Porque el papa Juan Pablo II es jefe, tipo hizo mucho por la iglesia y más que él fue el que aceptó muchas cosas de la ciencia y pidió perdón por muchas cosas que se hicieron antes, o sea, que jueguen con él así en una película por, ok a lo mejor y no implícito pero fue un mensaje como que no subliminal porque eso no existe, pero no sé no me gustó (Patricio-22)

En nuestro estudio sólo fue posible identificar 11 comentarios de desafío y cuatro de deconstrucción para un total de 15 comentarios de ambos tipos. Una declaración de desafío requería aserciones concretas en contra del contenido con alguna explicación alternativa. Un solo estudiante hizo tres de los cinco comentarios de este tipo codificados en la investigación. En el siguiente ejemplo, el joven es capaz de criticar la veracidad de la historia y la confronta con datos alternos provenientes de otras fuentes. Este informante afirmó que,

Ah, obviamente sí fue de que le dije: hey, es ficción, o sea compararlo con lo que dice la Biblia y obviamente el autor del 
libro te dice es ficción o sea nada de esto es verdad o sea si se basa en historia real como el cónclave, la iglesia y todo eso pero todo es, son como que mitos que junto pero todo es ficción y se lo dice Dan Brown (Patricio-22)

Yo digo que sí lo pueden llegar a ver como verdadero y sí puede llegar a mover a alguien de que a pensar de que ah bueno así se hacen las cosas y si hay cardenales así y si hay personas que se mueven por la ambición nada más y la iglesia es así pero creo que al ser una película también se puede malentender muchas cosas por lo mismo que es ficción y por lo mismo que tienes que investigar de que ok ya vi que es ficción pero investiga qué es lo que está bien y qué es lo que está mal (Patricio-22)

Conrespectoala deconstrucciónyasumiendo que ésta se refiere a una identificación precisa o crítica de procesos ideológicos, solamente fue posible codificar cuatro en el estudio de esta categoría. Un ejemplo es:

Este te digo, es una película de acción pero que incluye cierto tipo de historias relacionadas con la religión y pues antecedentes o acciones este que podrían causar algún tipo de impacto ¿No? Es una película que trata el tema de la religión católica... este... con ciertos tintes políticos y con grilla. Una apelación a difundir una ideología ¿No? (Alfonso-24)

Cabe resaltar el reducido número de aserciones oposicionales de tipo desafío o deconstrucción. Destaca la dificultad de los jóvenes para deconstruir ideología dentro del texto fílmico. El siguiente comentario muestra cómo un estudiante está consciente de algunos procesos ideológicos relacionados con la narrativa de la película pero es incapaz de identificarlos o describirlos con claridad. Intenta darle seguimiento al debate entre la ciencia y la fe tal como se representa en el guión de la película, pero parece tener dificultades al tratar de deconstruir el texto. Más aún, se nota confundido al diferenciar la realidad de su representación en el filme:
Yo creo que, como dijeron igual en la película, que, mucho menciona el actor Tom Hanks, que es la antimateria, o el anti-Dios, entonces yo creo que, a fin de cuentas, la Iglesia y Dios son dos cosas que van de la mano, quieras o no, por qué, porque igual que la Iglesia va evolucionando, porque antes a lo mejor los padres se podían casar, los padres podían tener territorios, y ahorita los padres solamente pueden ser solteros, solamente pueden ser personas que no hayan tenido relaciones, o sea, con ciertas especificaciones que necesitas para ser padre, y así igual la Iglesia pues va evolucionando de ciertas formas. Y pues, como estuvieron juntas en un principio, se pudieron llegar a separar, y en un futuro se van a poder llegar a juntas. Entonces yo creo que, en la película te mencionan un momento que la Iglesia y la ciencia van de la mano, aunque a lo mejor no se puede apreciar mucho, por qué, porque la Iglesia cree en cosas que no son firmes, y la ciencia trata de probar cosas que no están probadas, entonces, quieras o no, la misma cosa, que puede ser lo que no está firme y lo que no está probado, viene siendo lo mismo. Al final de cuentas, puede llegar a ser un Dios, puede llegar a ser Jesús, puede llegar a ser María, puede llegar a ser la antimateria. Entonces yo creo que, la película te lo trata de mostrar así como que, sí están separadas, y cada uno cree en sus distintas cosas, porque la mayoría de los científicos llegan a ser ateos, y la mayoría de los cristianos creen en una fe que no llegan a ver, pero a fin de cuentas, los dos están creyendo en algo que no han visto, pero están convencidos de que eso existe, y que pues, puede llegar a ser la antimateria, puede llegar a ser Dios, puede llegar a ser cualquier cosa X o Y, que puede llegar a existir, se puede llegar a comprobar, pero hasta ahorita en este momento, pues todavía no se ha llegado a ese punto. Entonces, yo creo que, lo toman de una manera imparcial, como que sin ningún lado, porque te llega a poner los dos puntos de vista (Alejandro, 20)

La mayoría de los jóvenes consideraron la película como entretenimiento desprovisto de cualquier postura ideológica. Muchos de ellos simpatizaron con el tema de la historia y su pro- 
puesta de representación de la Iglesia Católica. La deconstrucción no parecía ser un proceso frecuente o consciente. Si en este filme se considera la descripción de la Iglesia Católica como un significado alternativo podría ser considerado como una postura oposicional que los jóvenes estuvieran de acuerdo. Sin embargo, adicionalmente a las preocupaciones teóricas de Schroder (2000) en esta línea y como se discutió anteriormente, no encontramos ninguna evidencia de que los jóvenes concordaran con esta postura por estar conscientes de sus implicaciones ideológicas o de que fueran capaces de realizar observaciones críticas sobre la Iglesia en la vida real.

Debido al gran número de aseveraciones no oposicionales hechas por los jóvenes de la muestra, decidimos enfocar el estudio en el análisis de estas expresiones. Como ya se ha discutido antes, Palmer and Hafen (1999) construyeron las siguientes dos categorías para audiencias no críticas en su propio estudio de lecturas de adolescentes alemanes sobre programas televisivos norteamericanos: a) aceptación ingenua y b) aceptación sofisticada. En el primer caso, el receptor no distingue entre el texto y la realidad, y la discusión de los personajes o eventos no reconoce ninguna diferencia entre la vida real y su representación. El segundo caso se refiere a un acuerdo entre el espectador y la posición del texto en sus propios términos.

Dentro de la categoría de aceptación ingenua, los autores encontraron que muchos comentarios eran en relación con los personajes de las historias, particularmente que se enfocaban en su apariencia, fortalezas o debilidades y se referían a ellos con gran familiaridad. Dentro de nuestros propios hallazgos de aserciones no oposicionales, pudimos, además, reconocer que un número importante de comentarios hechos por los jóvenes seguía esta misma línea. Por ejemplo:

Sí, es que se me quedó muy marcado como que al final lo divino es lo que sale triunfando, por ejemplo, ya al final cuando al parecer todo estaba... cuando el Camarlengo estaba como que manejando todo muy bien, al fin de cuentas se sabe la verdad y... o sea, obviamente se dan cuenta, y triunfó y fue Papa, realmente fue Papa una persona que era realmente buena (Ana - 20).

En la categoría de aceptación sofisticada, las expresiones de los adolescentes en el estudio de Palmer y Hafen (1999) revelaban las razones por las cuales los jóvenes veían esos programas norteamericanos. Estas razones tenían que ver con su curiosidad por la historia o su interés en las relaciones entre los personajes o situaciones y su grado de realismo en la interacción de familias y personajes (pp. 139-141).

Estas categorías fueron muy útiles en nuestro propio estudio con los jóvenes de Monterrey ya que un gran número de aseveraciones no oposicionales son equivalentes a los comentarios que encontraron Palmer y Hafen. Uno de los informantes expresó que:

Pues estuvo interesante el tema pues... me gustó la trama que una pista te llevaba a otra, me mantuvo entretenido (Ramiro-21).

\section{Más allá de Encoding/decoding}

Schroder (2000) señala que el modelo de Hall (encoding/decoding) está principalmente diseñado para estudiar la recepción de significados dominantes, y excluye los alternativos. Bajo esta premisa, Schroder sugiere un modelo multidimensional. El contenido de Ángeles y Demonios es suficientemente contradictorio en sus mensajes ideológicos y religiosos, pero los jóvenes parecen estar de acuerdo con este contenido. Cohen (2002) arguye que, con frecuencia, la posición ideológica del texto no es clara o sin disputa, lo que vuelve difícil determinar si presenta una posición dominante o alternativa (p. 258). Como mencionamos anteriormente, el filme representa a la iglesia como una institución poderosa provista de intrigas mundanas y conspiraciones, lo que vuelve al texto posible de ser catalogado como alternativo y anti-hegemónico. En ese caso, como lo sugiere el autor, algunas de las posturas de los jóvenes con respecto a este contenido en particular pueden ser consideradas como lecturas oposicionales y conservadoras ante los aparentes 
significados alternativos del filme, en caso de que fuesen considerados así:

Me gustó la ficción de la película, porque primeramente hay que entender que esto, lo que se está viviendo, es una novela, entonces al mencionar novela yo lo relaciono directamente con la ficción, porque es algo que no pasó y eso yo digo que es donde mucha gente enloquece a veces. Por ejemplo, mi hermana, no quería ir a Ángeles y Demonios porque atacaba a la Iglesia, y pues, no deja de ser una película meramente de ficción, o sea, eso hay que dejarlo muy claro. Lo que me gustó fue la representación de la Iglesia, aunque es un poco fuerte la representan bien, la representan conservadora, como debe de ser, este... hubo unos ámbitos que no me gustaron pero si quieres al rato te los menciono, y...lo que no me gustó fue pues prácticamente, la presentación de la información en la película, porque de repente va muy lenta, no se mueve la película está muy... muy trabada, como lo puedes ver al inicio, donde no se veía que prácticamente nada fuera a pasar. Y de repente te avientan un Thriller de 20 minutos intenso, y luego la vuelven a parar... y eso a mi no me gusta porque no se disfruta, no se disfruta como lo disfrutas en un libro... eso fue lo que no me gustó, pero en sí la película es muy buena. (Alejandro-19)

Como se muestra en la tabla 2, un número importante de estudiantes no mostró propensión a deconstruir, desafiar o incluso criticar el contenido de la película. En este estudio, analizamos el acuerdo de los jóvenes con el filme y su habilidad para distanciarse de un texto ideológicamente ambiguo considerando que las categorías de lecturas preferentes u oposicionales resultan problemáticas. Al darle seguimiento a este modelo multidimensional, la mayoría de los jóvenes concordaron con las premisas del texto y tuvieron problemas para hacer críticas de fondo o desafiar las representaciones propuestas en la historia.

Ajá pero pues digo es parte de un libro, ¿no? A lo mejor es ficción eso, lo más verdadero es que pues te cuenta la historia, se supone que lo más real que puedes ver o te puedes dar cuenta es la historia de que los papas y que es lo que pasa y el pasado de los grupos que existían en el vaticano y todo eso. (Gabriela-19)

El modelo de Schroder (2000) incluye cuatro dimensiones de "lecturas" en la recepción que son: motivación, comprensión, discriminación y posición, "todas preocupadas por lo que podemos llamar procesos 'internos' de lectura en donde los significados basados en una subjetividad de la experiencia de los informantes se producen en contextos de situaciones específicas" (p. 243).

Como este modelo afirma, la motivación incluye los procesos tanto cognitivos como afectivos y va más allá de los textos mediáticos al destacar toda la experiencia de consumo. La situación holística es la base de la subjetividad implícita en la experiencia de ir al cine.

Pues sí, me gustó en general la película, las actuaciones se me hicieron muy reales, también el lugar donde se desarrolla a mí me gusta mucho Italia, de hecho quiero aprender italiano, y pues sí, me gustó el contexto en que se desarrolla y todo eso. ¿A ti te gustó la película? (Ramiro-19).

Dentro de la categoría de comprensión, los informantes algunas veces pueden "ser radicalmente divergentes, y la gente puede perderse al darle sentido al mensaje mediático" (p. 247).

Ah, sí es cierto, verdad, porque en la película dicen que se muere del accidente del helicóptero y lo hacen gran héroe, cuando en realidad se quema por la traición que le hace a la iglesia, no. Yo opino pues que definitivamente ahí lo que están haciendo es proteger los intereses, que posiblemente sus creyentes no se den cuenta de un complot interno, porque pues imagínate la desestabilización, este...que generaría dentro de la religión no, posiblemente pierdan creyentes, posiblemente se den cuenta que realmente existe mucha grilla mucha política, mucha persecución del poder, muchos intereses, y pues que al final del día, pues te puede llegar a afectar no, este... si está bien o está mal no lo sé, pero yo creo que sí... definitivamente cualquier organización, 
este... religiosa, lucrativa, no lucrativa, de política, pues debe de, pues manejar de manera adecuada su información para ese tipo, o cuando tienes ese tipo de sucesos pues que no se genere un impacto en tu medio, por ejemplo, en nuestro medio de la medicina cuando tienes algún problema, cuando tienes este, algún diagnostico, pues siempre tienes que manipular la información, lo mas que se pueda para no causar un impacto no, para proteger a los médicos, para proteger la paciente, para proteger a la familia, entonces digo no estoy en contra, aunque pues obviamente esta, no mal, pero, no yo creo muchas veces es necesario, no manipular pero... (Alfonso-24)

La dimensión de discriminación parece muy útil para comprender el grado de conciencia en la construcción del texto mediático en las lecturas de los jóvenes sobre Ángeles y Demonios. Esta discriminación estética puede ser visualizada como un continuo de inmersión en un extremo y un distanciamiento crítico en el otro. Por ejemplo, Schroder (2000) sugiere que las audiencias pueden percibir un mensaje como una representación transparente e incuestionable de la realidad social sin desarrollar una evaluación crítica del texto. En nuestro estudio, el gran número de lecturas no oposicionales comprueba el caso. Un ejemplo de lo anterior es:

Pues como el autor de estas historias como es Dan Brown como siempre la ha hecho ver a la iglesia, como un ente de gran poderío que mantenía muchísimos secretos pero al final estuvo diferente ya que hizo ver a la iglesia como si tuviera mucha fuerza, triunfando los buenos pero al mismo tiempo se hizo muy presente de los secretos que se siguen escondiendo en su historia. (Alfredo-21)

Por supuesto una interpretación diferente de este tipo de expresiones concluiría que los jóvenes estaban de acuerdo con el significado alternativo del filme con respecto a sus propias mediaciones culturales y sociales, o incluso a pesar de ellas ( si se proclaman a si mismos de creencia católica). Sin embargo, como se explica arriba, nuestro estudio se centra en la actividad y habilidad de los jóvenes para distanciarse de la película, lo cual no encontramos en la mayoría de sus respuestas y comentarios. Por ejemplo, después de estar de acuerdo con la descripción que se ofrece en Ángeles y Demonios sobre el Vaticano, no se cuestiona ningún aspecto corolario como la representación, el contenido, la falta de veracidad, la subordinación de los italianos y las mujeres al héroe americano, la legitimación de la violencia o cualquier otro significado problemático del filme. Entonces, en nuestro estudio, preferimos enfocarnos solamente en la "actitud subjetiva del texto que acompaña a la lectura" (Schroder, 1999, p. 249). Para el autor, el concepto de posición

... incluye un continuo de respuestas referentes a la actitud, desde la aceptación hasta el rechazo de la postura percibida en el texto y los variados elementos textuales percibidos que conforman esa postura. Como las otras dos dimensiones de lecturas, la posición adoptada por el espectador hacia el texto debe ser conceptuada como un proceso de "permutar", no obstante respuestas de aceptación o rechazo de manera estable e inequívoca son concebibles. (p. 249).

En esta dimensión, la aceptación no significa la adopción de un contenido hegemónico sino el acuerdo con lo que se considera el mensaje del texto. Como un ejemplo de lo anterior, uno de los jóvenes dijo;

Bueno este, a mí se me hace que hizo muy buena investigación, de hecho después de leer el libro me fui a ver su pagina de Internet, porque pues en el libro viene la referencia y te muestra la investigación como que mas detallada sobre lo de los illuminati y todas estas cosas, estos los símbolos que se leen igual a derecho y al revés, ósea tiene como que base histórica, pues la película, si es mucha imaginación, ósea demasiado , pero lo sabe mezclar muy bien con cosas que si son reales, o cosas incógnitas que esta como que sin saber todavía, todavía no sale o no se comprueba si son ciertas o son falsas eso como que, te da el morbo de estar leyendo o así de saber (Carlota-21). 
En suma, más allá de un significado dominante o alternativo de Ángeles y Demonios, queda al descubierto que la mayoría de los informantes no encontraron problemáticos los contenidos ideológicos o políticos de la película. Un gran número de jóvenes hicieron interpretaciones ingenuas, o en el mejor caso, interpretaciones sofisticadas en aceptación al texto.

\section{Mediaciones}

Tal como Cohen (2002) sugirió en su investigación de Ally McBeal, este estudio se enfoca en las audiencias y cómo éstas construyen sus propios significados. Siguiendo la tesis del autor, establecer un significado "verdadero" de la película y tratar de vincular las etiquetas de "dominante", "negociado" u "oposicional" a lecturas particulares resulta menos importante que encontrar qué distingue a los espectadores que refrendan distintas lecturas (p. 258). En esta línea, analizar los marcos de interpretación de los jóvenes es útil e ilustrativo.

En la tradición latinoamericana, un grupo de reconocidos académicos ha discutido la importancia de las mediaciones sociales y culturales en las lecturas ideológicas de los miembros de las audiencias (González, 1991; Martín Barbero, 1987; Orozco, 1991). La pluralidad de los discursos y la multiplicidad de significados potenciales de los que hablaba Hall (1985) en las interpretaciones de las audiencias se encuentran constantemente influenciadas por estas mediaciones.

Para seguir el modelo multidimensional tomado del trabajo de Schroder (2000), nos hemos enfocado en la ideología y subjetividad de los estudiantes que los influencia a criticar o aprobar el texto. En nuestro estudio, pudimos identificar por lo menos un comentario por cada participante entrevistado en el cual las mediaciones sociales, familiares o religiosas sirvieron como marco de referencia para interpretar el texto, produciendo así lecturas tanto oposicionales como no oposicionales. Es importante resaltar que en el caso de las entrevistas, este tipo de expresiones eran considerablemente más frecuentes. Un ejemplo de un comentario enmarcado por una mediación es el siguiente;

Mira... yo este, me habías preguntado si tenía una religión ¿no? Bueno si soy cristiana, este y siempre he tenido así como que dudas con los católicos pues y mas con la iglesia así en general y yo creo que la mayoría de las personas o sea así, las tienen y si, es como que ha tenido pasados oscuros así de que la inquisición y todo eso y este, como que estas leyendo algo que diga que pues o sea, era posible que, io sea! Dan Brown se enfoca mucho en como que en la iglesia, desde el código DaVinci (A: si), , de que, que habían hecho malas acciones y eso, cosas que se saben pues pero que no se están diciendo tonces como que todo eso que esta alrededor como que la investigación como que ver que al final, ver que era un padre o sea que era malo todo así pero sin atacar tanto a la iglesia este si te llama la atención bueno a mi si no tanto que los iluminati es muy interesante lo que dicen que hicieron, te digo estos símbolos que este , esta relación con personas históricas muy famosos y muy intelectuales y que la separación entre la ciencia y la religión y que luego, o sea con esta historia se supone que el que en este caso es el villano que es el padre lo que quería era juntarlos o sea relámete como que fuera uno mismo que la gente ya no lo tomara como que por separado, que ya no estuviera tan cerrada acosas nuevas , porque pensaban que no va este con su religión eso es lo que o sea me llama la atención. (Carlota-21)

Al considerar el tema general de la película, la religión ligada a la experiencia familiar apareció como la mediación más relevante. Uno de los estudiantes se distanció claramente del texto fíl mico cauteloso ante su crítica abierta a la estructura católica. Sus firmes convicciones le permitieron diferenciar la historia de una película con lo aprendido de su familia y grupo de referencia religioso;

Lo que estamos analizando aquí son dos cosas distintas. Yo no puedo meter mi religión en una sala de cine, como te digo, el cine es meramente un arte para entretener 
a las personas, al pueblo. Entonces, cuando tú me preguntas que si eso me ofendió, yo no puedo decir que sí porque un entretenimiento no agrede a nadie (Alejandro-19).

Alfredo mostró gran convicción sobre sus creencias religiosas;

No, pero... creo que cada persona que va a al cine a ver estas películas debe de esta conciente de que no es nada mas que esto, solamente una película que esta basada en un libro y que no es algo verídico no es... no son hechos que tienen fundamentos o son verídicos es simplemente una película basada en un libro y ya, ósea no debemos tomar, nosotros los espectadores, como verdad todo lo que estamos viendo ahí en la pantalla grande, y también creo que todos tenemos que tener nuestras ideas firmes y nuestras creencias y pues creo que al momento de ver una película, como es Ángeles y Demonios, no es o era del todo creyente al momento que solo una película afecte la creencia o la percepción en la iglesia y que esta sea lo único que te va a llevar o motivar a mover tu percepción ya que pues debemos haber tenido una... bueno entre paréntesis aquí haciendo un espacio yo me considero católico y siempre eh tenido la educación de mis padres de ser y que me han inculcado el catolicismo desde pequeño, entonces en lo personal yo no siento que haya cambiado mi percepción sobre la iglesia católica pues debido a todo esto, a la fuerte influencia de mis padres y demás, familiares, amigos, etc. y mis creencias pues personales frente a esto mismo. (Alfredo-21)

El efecto de las creencias religiosas en la recepción de una película como Angeles y Demonios es complejo y está lejos de provocar en los jóvenes una lectura oposicional en su conjunto. Como la cita de arriba refiere, algunos jóvenes fueron capaces de negociar sus propias creencias y volverse un tanto flexibles como para disfrutar una película crítica de la institución a la que ellos mismos pertenecen. Incluso cuando en alguna experiencia social compañeros o miembros de su comunidad católica manifestaron desacuerdo con el contenido de la película, los jóvenes de nuestro estudio justificaron su interés y defendieron su derecho a leer o ver contenidos de ficción argumentando que eran capaces de diferenciar una novela de la realidad. Uno de los informantes platicó sobre su experiencia con una maestra que trató de interferir en sus preferencias literarias;

En prepa, yo, cuando estaba leyendo ese libro, yo estudié en al prepa UDEM mi prepa, ¿no? Entonces, lo estaba leyendo en clase, y mi maestra de que me lo quitó, y me sacó del salón, y super histérica, me mandó a la dirección casi creo. Me sacó a una plática aparte especial para hablar de mi fe, y yo d que: "Pues es un libro de...iEs una novela!" [HACIENDO LA VOZ MÁS GRAVE] "iNo deberías de leer! iEs un mugrero en contra de la Iglesia! Padre Santísimo!" y casi creo que me crucifica, la pobre mujer estaba histérica. Pero yo le decía "Pues es que, mi fe es mi fe, y mi lectura es mi lectura. Igual y sí hay gente que le va a dudar, porque pues vienen cosas que están escritas de una manera que claro que parece que todo lo que dicen es real, que lo lees y dices de que "iiihhh! El papa hizo esto!" Es una lectura, no te dejes envolver. Es una película, no te traumes. No sé, pero sí siento que hay gente que puede su fe tambalearse. Si no es una persona que tiene su fe bien puesta, con ese tipo de películas puede tener dudas o puede decir "iay sí! La Iglesia es así!" (Daniela-20)

Como se puede observar en estos ejemplos, las mediaciones sociales son relevantes en los procesos de descodificación, en tanto que actúan como filtros complejos entre el texto fílmico y la interpretación final de los jóvenes. Aún así, éstas coexisten con percepciones y lecturas indulgentes en las dimensiones ideológicas del filme.

\section{Discusión}

El propósito principal de este trabajo fue explorar e identificar el tipo y la intensidad de lecturas oposicionales y críticas realizadas por un grupo de jóvenes mexicanos sobre la controversial superproducción de Hollywood Ángeles y Demonios, 
así como la importancia de mediaciones sociales y culturales como la familia y las creencias religiosas en la variedad y la intensidad de dichas descodificaciones oposicionales.

El estudio tomó como su punto de partida, al igual que han hecho autores como Schroder (2000) y Cohen (1999) , una versión revisada del modelo encodificación/descodificación, permitiendo el análisis de lecturas oposicionales o negociadas de significados alternativos en un texto mediático y enfocándose más en la habilidad de los espectadores para ser activos y críticos frente a cualquier significado en un filme, específicamente cuando son tan ambiguos como los que se presentan en la película Ángeles y Demonios.

Usando las categorías de grados de resistencia y deconstrucción propuestos por Hacker, Coste y Kamm (1991), encontramos que una muestra de jóvenes estudiantes de una universidad privada de Monterrey fueron por lo general incapaces de elaborar comentarios críticos sobre el contenido ideológico de la cinta. De manera similar a lo encontrado por Hacker, Coste y Kamm sobre la descodificación de noticias por parte de su muestra de estudiantes, los jóvenes de Monterrey realizaron principalmente-en sus pocas aseveraciones críticas-comentarios de "crítica" y "resistencia", las posturas oposicionales menos elaboradas (sin argumentos o con mínimos argumentos para apoyarlas). Pese a sus fuertes convicciones religiosas, los estudiantes no parecían en desacuerdo con el contenido general del filme; en su mayor parte, consideraron justa la representación de la Iglesia. Los comentarios clasificables en las categorías de "desafío" o "deconstrucción" fueron muy escasos, confirmando otros hallazgos de estudios empíricos basados en los estudios culturales sobre la existencia de ciertos límites en la capacidad crítica y negociadora de las audiencias. Hacker et al., (1991) por ejemplo, encontraron que estudiantes universitarios eran capaces de señalar que las noticias televisivas estaban sesgadas e incluso que buscaban conscientemente la manipulación (p. 197). Sin embargo, encontraron que a pesar de esa posición crítica sobre los sesgos y la falta de objetividad, los estudiantes no esta- ban conscientes de las formaciones o discursos ideológicos en la información" (p. 198). Sigman y Fry (1985) llegaron a una conclusión similar, al encontrar que mientras que algunos lectores de periódico encuestados por ellos eran capaces de identificar posiciones y sesgos ideológicos en ellos, había otros que pensaban que las noticias eran sustantivas, objetivas y basadas en hechos. Encontraron, asimismo, que cuando se les solicitaba explicar en sus propias palabras eventos específicos controversiales, los lectores definitivamente adoptaban los mismos marcos de referencia e incluso la misma terminología que usaban los periódicos que habían leído, lo que confirmaba que los textos noticiosos organizan en cierto modo la comprensión de los eventos por parte de los lectores. No es fácil determinar si esta escasez de lecturas "desafiantes" o de "deconstrucción" es exclusiva para noticias y filmes pero no para otros mensajes mediáticos que pudieran ser más relevantes o más cercanos a las preocupaciones de la vida cotidiana de las personas, como las series dramáticas (soap operas) y las telenovelas latinoamericanas. De acuerdo con la literatura culturalista, este tipo de programas televisivos generan interpretaciones muy activas y críticas por parte de sus audiencias (cfr. Ang, 1985; Covarrubias y Uribe, Hobson, 1989; La Pastina, 2007; Liebes y Katz, 1990; Tufte, 2000; Seiter, Borchers, Kreutzner y Warth (1991); Vasallo de Lopes, Borelli y Resende, 2002). Debido a que en estos estudios no se utilizaron categorías desglosadas para el tipo de lecturas críticas u oposicionales (de hecho varios de ellos no utilizaron siquiera las categorías generales de lecturas preferentes, negociadas y oposicionales) es difícil establecer si en realidad hay ciertos géneros y tipos de mensajes más propensos que otros a generar criticismo por parte de la audiencia. Por lo pronto, la evidencia sugiere que para el caso de noticias televisivas y, por lo menos algunas películas de Hollywood, es poco común encontrar lecturas oposicionales sofisticadas y son más abundantes las oposicionales "ingenuas".

La mayoría de los informantes, sin embargo, fueron capaces de establecer diferencias entre 
la Iglesia Católica en el mundo real y la representación de la misma por parte de la película. Muchos de ellos mostraron una posición relativamente oposicional cuando el texto contradecía sus creencias religiosas, lo que evidencia la importancia de las mediaciones familiar y religiosa. En este sentido, aunque incapaces de articular comentarios fuertes y argumentados sobre los significados y posiciones ideológicas de la cinta, fueron suficientemente activos para impedir que la descripción de la Iglesia Católica y del Vaticano en la cinta contradijera sus propias creencias religiosas previas. El interés de los jóvenes en acudir a las salas cinematográficas a ver una secuela de una película previa (El Código Da Vinci) ampliamente criticada por el Vaticano y organizaciones católicas muestra que la dimensión de disfrute derivada de la exposición a superproducciones de Hollywood, aunada a la expectativa generada por la controversia religiosa de su antecesora, los motivó a entretenerse con Ángeles y Demonios mientras rechazaban al mismo tiempo sus referencias negativas hacia sus autoridades religiosas y sus creencias. Esto pudo ser más fácil en esta película que en la anterior. En contraste con El Código Da Vinci, más clara en su crítica al Vaticano y en su desviación de la ortodoxia católica, Ángeles y Demonios resultó más ambivalente en su tratamiento de dicha Iglesia, ensalzando al Papa asesinado por su intento de reconciliar la ciencia y la religión y al culpar exclusivamente a un personaje confundido, el camarlengo.

Nuestros hallazgos muestran que la descodificación de películas de Hollywood, al menos de producciones que no se centran en la descripción de la cultura norteamericana, en lugares donde el descuento cultural es grande debido a diferencias en lenguaje, religión y cultura, no es tan oposicional y crítica por más activos que sean los miembros de las audiencias. Mediaciones como el alto nivel socioeconómico, la alta educación o las firmes creencias religiosas no resultaron tan decisivas en sus lecturas e interpretaciones de Ángeles y Demonios. Los informantes no eran ciertamente tan crédulos ni pasivos al descodificar el filme y no parecieron cambiar sus creencias y actitudes previas hacia sus autoridades religiosas después de exponerse a ella, pero no mostraron mayormente ni capacidad ni interés en deconstruir la película mediante un distanciamiento racional y una posición crítica hacia sus valores e influencias ideológicas de producción. Quizá, de haberse seleccionado una superproducción de Hollywood más común y corriente, centrada directamente en la cultura estadounidense y en temáticas menos intrusivas que la religiosa, los tipos de lecturas habrían variado de manera significativa. Sin embargo, nuestros hallazgos parecen coincidir con los de Biltereyst (1991), quien en el caso de televidentes flamencos de series de ficción norteamericanas (centradas precisamente en dicha cultura), concluyó que sus informantes realizaban lecturas lineales, cerradas y consensuadas de las comedias de situación de dicho país (p. 491): "si negociar se refiere a un proceso de intercambio entre la posición real del espectador y la propuesta por el texto...en este caso las acciones negociadoras entre el grupo de receptores y la comedia de situación norteamericana no se veían excepcionalmente desarrolladas".

Un solo estudio centrado en estudiantes universitarios con un nivel socioeconómico alto no es capaz de determinar las diferentes lecturas realizadas por todos los tipos de públicos que en México vieron Ángeles y Demonios. Futuros estudios deberán centrar su atención en otros segmentos del público y en otras películas de Hollywood para establecer si la cantidad de comentarios no oposicionales se mantiene y si las críticas y la resistencia (las aseveraciones oposicionales más superficiales) siguen siendo las más comunes. Además, los futuros estudios deberán tratar de afrontar un aspecto aún más controversial del modelo de encodificación-descodificación y su propuesta de clasificar como preferentes, negociadas u oposicionales las lecturas realizadas por las audiencias. Aunque no de manera explícita, el modelo parece sugerir que las lecturas preferentes podrían guiar hacia el "adoctrinamiento", el reforzamiento, adopción o internalización de definiciones y posiciones hegemónicas. Pero en la práctica no queda claro si realizar lecturas no oposicionales de una película o programa de televisión equivalga a una influencia ideológica del 
texto. En este estudio, los respondientes estaban en lo general de acuerdo con el contenido y los encuadres de Ángeles y Demonios, pero no transferían las críticas y las representaciones problemáticas del Vaticano en el filme a las autoridades ni al funcionamiento reales de la Iglesia Católica. Identificar y evaluar el impacto efectivo del contenido ideológico de las películas podría ser más difícil y complejo que simplemente analizar la intensidad de las lecturas no oposicionales realizadas por los espectadores.

Por el momento, podemos afirmar que las lecturas oposicionales o negociadas no eran tan frecuentes y fuertes en este segmento del público y que hay cada vez más evidencias dentro de los estudios culturales que sugieren que no es suficiente argumentar teóricamente que la audiencia es activa y capaz de realizar descodificaciones negociadas de los contenidos mediáticos: sólo la investigación empírica puede proporcionar evidencias y entendimiento del grado real de crítica y deconstrucción de las películas estadounidenses por parte de segmentos específicos de las audiencias. Como planteaba Biltereyst desde 1991, "si logramos entender cómo las audiencias fuera de los Estados Unidos consumen, experimentan y descodifican la ficción norteamericana, podremos tener una visión más precisa de su potencial influencia" (p. 470). Más de 20 años después, aún tenemos un gran déficit en la cantidad de estudios empíricos que se enfoquen en la recepción de ficción estadounidense fuera del país que la produce.

\section{Referencias bibliográficas}

Ang, I. (1985). Watching Dallas: soap opera and the melodramatic imagination. Londres, Nueva York: Methuen.

Beltrán, L. R., y Fox de Cardona, E. (1980). Comunicación dominada. México: ILET.

Biltereyst, D. (1991). Resisting American Hegemony: A Comparative Analysis of the Reception of Domestic and US Fiction. European Journal Of Communication, 6(4), 469-497.

Box office mojo: An Imdb company. (2010). Obtenida el 15 de octubre de 2010 de http://boxofficemojo. $\mathrm{com} / \mathrm{movies} /$ ?page $=$ intlEid $=$ angelsanddemons. htm

Cohen, J. (2002). Deconstructing Ally: Explaining viewers' interpretations of popular television. Media Psychology, 4(3), 253-277.

Covarrubias, K., y Uribe, A. (2001). Hacia una nueva cultura televisiva: Mirada de Mujer en la percepción de los públicos colimenses (resultados de investigación). Estudios sobre las Culturas Contemporáneas, 7(14), 89-126.

Dirks, T. (2010). All-time top 100 box office films Obtenida el 30 de octubre de 2010 de http://www. filmsite.org/boxoffice.html

Dorfman, A., E Mattelart, A. (1975). How to read Donald Duck: imperialist ideology in the Disney comic. Nueva York: International General.

Esteinou, J. (1983). Los medios de comunicación y la construcción de la hegemonía. México: Nueva Imagen.

Esteinou, J. (1994). Televisión nacional y globalización cultural: el caso de México. Anuario de Investigación de la Comunicación CONEICC, 1, 47-70.

González, D. (2007). Sueño Americano en México. Televisión estadounidense y audiencias juveniles en Tijuana. Mexicali, México: Universidad Autónoma de Baja California.

González, J. A. (1991). Más (+) Cultura (s). Ensayos sobre realidades plurales. México, D.F.: CONACULTA.

González, J. (1998). El regreso de la cofradía de las emociones (in)terminables: telenovela y memoria en familia. En J. González (Comp.), La cofradía de las emociones (in)terminables, (pp. 163-181). Guadalajara, Jal.: Universidad de Guadalajara.

Guadarrama, L. A. (1999). Dinámica familiar y televisión. Cuadernos de Investigación de la Universidad Autónoma del Estado de México.

Hacker, K., Coste, T. G., Kamm, D., \& Bybee, C. (1991). Oppositional readings of network TV news. Discourse and Society, 2(2), 183-202.

Hall, S. (1980/2001). Encoding decoding. En M. Gigi Durham \& D. M. Kellner (Eds.), Media and cultural studies. KeyWorks (pp. 166-176). Malden, MA: Blackwell Publishing. 
Hall, S. (1985). Signification, Representation, Ideology: Althusser and Post-structuralists debates. Critical Studies in Mass Communications, 2(2), 91-114.

Hobson, D. (1989). Soap operas at work. En E. Seiter, H. Borchers, G. Kreutzner y E.-M. Warth (Eds.), Remote control: Television, audiences \& cultural power (pp. 150167). Nueva York: Routledge.

Huerta, J. E. (2004). "No le cambies a mi novela". Dominación y negociación entre géneros en el acto de ver televisión. Comunicación y Sociedad(1), 163-182.

Jacks, N. (1993). La identidad cultural como mediación simbólica. Comunicación y Sociedad (18-19), 17-32.

La Pastina, A. (2007). Telenovela reception in rural Brazil: Gendered readings and sexual mores. En $\mathrm{H}$. Newcomb (Ed.), Television. The critical view (7th ed., pp. 486-506). Nueva York: Oxford University Press.

La Pastina, A. C., y Straubhaar, J. D. (2005). Multiple Proximities between Television Genres and Audiences: The Schism between Telenovelas' Global Distribution and Local Consumption. Gazette, 67(3), 271-288.

Liebes, T., y Katz, E. (1990). The export of meaning: crosscultural readings of Dallas. New York: Oxford University Press.

Lozano, J. C. (2003). Consumo y lecturas negociadas de noticieros televisivos en Monterrey, Guadalajara y México, D.F. Estudios sobre las Culturas Contemporáneas, 9(18), 43-56.

Lozano, J. C., y Frankenberg, L. (2009). Theoretical approaches and methodological strategies in Latin American empirical research on television audiences: 1992-2007. Global Media and Communication, 5(2), 149-176.

Martín-Barbero, J. (1987). De los medios a las mediaciones. Comunicación, cultura y hegemonía. México, D.F.: GG Mass Media.

Martín-Barbero, J. (1988). Communication from culture: the crisis of the national and the emergence of the popular. Media, Culture \& Society, 10(4), 447-465.

Martín-Barbero, J. (2006). A Latin American perspective on communication/cultural mediation. Global Media and Communication, 2(3), 279-297.
Martínez, F., y Lozano, J. C. (2005). Flujos televisivos y cinematográficos en México. Comunicación y Sociedad (Nueva Época)(3), 47-66.

Mattelart, A. (1979). Multinational corporations and the control of culture: the ideological apparatuses of imperialism. Sussex, Atlantic Highlands, N.J.: Harvester Press; Humanities Press.

Meré, D. (2009, 2 de noviembre, 2009). Esquiva la crisis la industria del cine, Reforma, p. 5.

Meré, D. (2010, 6 de febrero, 2010). Crecen 10\% ingresos de cines, Reforma, p. 4.

Morley, D. (1980). The 'Nationwide' audience: Structure and decoding. Londres: British Film Institute.

Morley, D. (2006). Unanswered questions in audience research. The Communication Review, 9, 101-121.

Nightingale, V. (1996). Studying audiences: the shock of the real. Londres, Nueva York: Routledge.

Orozco Gómez, G. (1991). Recepción televisiva. Tres aproximaciones y una razón para su estudio. Cuadernos de comunicación y prácticas sociales 2. México, D.F.: Universidad Iberoamericana. Programa Institucional de Investigación en Comunicación y Prácticas Sociales.

Orozco Gómez, G. (1992). Familia, televisión y educación en México. La "teoría educativa" de la madre como mediación en la recepción televisiva de los niños. En G. Orozco (Ed.), Hablan los televidentes. Estudios de recepción en varios países. Cuadernos de comunicación y prácticas sociales 4 (pp. 11-32). México, D.F.: Universidad Iberoamericana. Programa Institucional de Investigación en Comunicación y Prácticas Sociales. Dirección de Investigación y Posgrado.

Palmer, A. W., y Hafen, T. (1999). American TV through the Eyes of German Teenagers. En Y. R. Kamalipour (Ed.), Images of the U.S. around the World. A Multicultural Perspective (pp. 135-146). Albany, New York: State University of New York Press.

Saintout, F. (1998). Los estudios de recepción en América Latina. La Plata, Argentina: Ediciones de Periodismo y Comunicación.

Schroder, K. C. (2000). Making sense of audience discourses: Towards a multidimensional model of 
mass media reception. European Journal of Cultural Studies, 3(2), 233-258.

Seiter, E., Borchers, H., Kreutzner, G., y Warth, E.-M. (1991). "Don't treat us like we're so stupid and näive": Towards an ethnography of soap opera viewers. En E. Seiter, H. Borchers, G. Kreutzner y E.-M. Warth (Eds.), Remote control: Television, audiences \& cultural power (pp. 223-247). Londres: Routledge.

"Synopsis for Angels and Demons". (2010). Obtenido el 15 de octubre de 2010 de http://www.imdb.com/ title/tt0808151/synopsis

Tufte, T. (2000). The popular forms of hope: About the force of fiction among TV audiences in Brazil. En I. Hagen y J. Wasko (Eds.), Consuming audiences? Pro- duction and reception in media research (pp. 275-300). Cresskill, New Jersey: Hampton Press.

Uribe, A. (1994). La telenovela en la vida familiar cotidiana. Apuntes de investigación. Estudios sobre las Culturas Contemporáneas, 5(15), 185-207.

Vasallo de Lopes, M. I., Simoes Borelli, S. H., y da Rocha Resende, V. (2002). Vivendo com a Telenovela: mediaçoes, recepçao, teleficcionalidade. San Paulo: Summus Editorial.

Vega, A. (2005). Construyendo Puentes: La identidad de género de los jefes de familia y la recepción televisiva. Comunicación y Sociedad (4), 127-145.

Yarto, C., y Lozano, J. C. (2004). Televisión, rutinas y vida cotidiana en mujeres de México, Guadalajara y Monterrey. Global Media Journal México, 1(1). 